\title{
Clinical diversity of Low Carbohydrate Diet (LCD)
}

\author{
Hiroshi Bando, MD, PhD \\ Tokushima University / Medical Research, Tokushima, Japan \\ ${ }^{*}$ Corresponding author: Hiroshi Bando, MD, PhD, FACP, Tokushima University /Medical Research, Nakashowa 1-61, Tokushima 770-0943 Japan; TEL: +81-90-3187- \\ 2485; E-mail: pianomed@bronze.ocn.ne.jp
}

Received: December 05, 2018; Accepted: December 12, 2018; Published: December 19, 2018;

\section{Commentary}

When observing the medical and health situation in the world, diabetes, obesity and metabolic syndrome have been crucial social problems in developed and also developing countries [1]. Especially, the diet therapy would be indispensable which can be continued for long years such as low carbohydrate diet (LCD) and Calorie restriction (CR). LCD was originally begun by Atkins and Bernstein before, and it has been known and popular until now. [2,3].

After that, there was a meaningful report from Dietary Intervention Randomized Controlled Trial (DIRECT) Group that showed the predominance compared with Mediterranean and Low-Fat Diet for 2 years [4]. Successively, DIRECT group reported the results for 4 years [5]. Thus, several researchers reported the predominance of LCD for weight reduction or $\mathrm{HbAlc}$ value [6].

In contrast, authors and colleagues have introduced and developed LCD in Japan for long years [7]. We have continued practice and research of LCD and activities of Japan LCD promotion association, including educational seminars, medical journals / books and presenting in medical society [8].

There has been lots of discussion about LCD and CR for years. LCD has rather superiority to CR diets and low-fat foods in the light of weight control and blood glucose variety in short period [4]. For more than 1 year or more, continuing discussion has found concerning the comparison of LCD and CR [9]. Some reports showed beneficial effect of LCD and others revealed unremarkable difference between them $[6,10,11]$.

There is a prospective randomized controlled trial (RCT) that LCD of $130 \mathrm{~g}$ /day for 6 months reduced HbAlc and BMI more than CR [12]. However, the benefit for LCD after intensive intervention has not always maintained in the light of HbAlc and BMI between LCD and CR. This study was continued and summarized one year after regarding the comparison between LCD and CR. The result showed the beneficial efficacy for the LCD on reduction of $\mathrm{HbAlc}$ and BMI, but improved levels did not persist compared with that of CR. However, when combined the data of both groups, HbA1c and BMI values were significantly decreased from the baseline. The superiority of LCD seemed to disappear 1 year after, but those results would suggest the comparative efficacy to improve $\mathrm{HbAlc}$ value at least 1 year [12].
As described above, the discussion of the clinical effect for LCD and $\mathrm{CR}$ has been continued for long years. However, we cannot induce the final conclusion which is superior. They are various factors involved in the evaluation and measurement of the both methods. The research has been not in vitro research or in vivo study of the same feeds to rat every day, but clinical meal study for human in their ordinary daily life.

In the primary care setting, general efficacy of LCD has been understood rather widely. On the other hand, a problem has been known about whether the LCD continuation is possible, or whether the effect of weight reduction is possible during rather long period. After a while, some patients return to their previous meal style [13]. There are some reports that the effect of LCD can be sustained rather long term [14]. Since there are various influential factors, it will be necessary to investigate related influence into detail analysis [15].

A recent report was found that revealed several results against the previous clinical effect for LCD. There has been the Atherosclerosis Risk in Communities (ARIC) Study which has continued its research development for some decades [16]. The ARIC study has many subjects more than 430 thousand for 25 years [17]. According to the results of ARIC cohort study, they have reported a U-shaped association between the percentage of energy of carbohydrate (mean $48.9 \%$, SD 9.4) and mortality, after calculating for multivariable adjustment. Furthermore, they calculated and compared the total carbohydrate ratio of the diet. As a result, daily meal including high $(>70 \%)$ percentage or low $(<40 \%)$ percentage of energy from carbohydrates were observed, in association with elevated mortality rate, and with minimal risk found between carbohydrate content ratio in 50-55\% [17].

In order to evaluate the optimal intake amount of carbohydrate for the guidance recommendations associated with certain medical evidence, the protocol included the population-based study of overall carbohydrate consumption [17]. Especially, it investigated the association of carbohydrate intake amount in accordance with mortality and residual lifespan levels. As a daily meal method, LCD was applied for reducing body weight and decreasing the cardiovascular and metabolic risk. At the same time, they recommended to replace of carbohydrate food with other proteins and plant-based fats. This procedure can give the subjects practical approach for daily healthy life in the light of anti-aging medicine [17]. 
In the practice and research on diabetes, how should we think about the relationship between clinical matters and the EvidenceBased Medicine (EBM)? [18] EBM has not only critically examined evidence, but also considered practicality, reality and individual tastes and situations. Short-term LCD has been effective by conventional reports and may increase the motivation feeling for progressive cure and care for the patients [19]. However, on the other hand, for longterm LCD, we have to consider the required daily calorie and also carbohydrate intake amount. Based on this situation, we would like to aim for Taylor-made diet therapy according to each patient, taking account of feasibility, continuity and safety $[20,21]$.

In summary, the discussion on the comparison of LCD and CR has been continued for years. The main point would be the clinical efficacy for rather long term. Each report includes each definition of LCD such as the different amount or ratio of carbohydrate in the food. Consequently, further accumulation of the data would be expected for future practice and research development.

Key words: low carbohydrate diet (LCD), Calorie restriction (CR), Dietary Intervention Randomized Controlled Trial (DIRECT), Atherosclerosis Risk in Communities (ARIC), Japanese LCD Promotion Association (JLCDPA)

\section{References}

1. Bando H (2018) Recent problems for the elderly life - diabetes, dementia, frailty. J Diabetes Metab Disord Control. 5(5): 167-169. DOI: 10.15406/ jdmdc.2018.05.00158.

2. Atkins RC (1981) Dr. Atkins' diet revolution. Bantam Books, New York. ISBN-10: 0553271571, ISBN-13: 978-0553271577.

3. Bernstein RK (1997) Dr. Bernstein's Diabetes Solution. Little, Brown and company, New York. ISBN 10: 0316093440, ISBN 13: 9780316093446.

4. Shai I, Schwarzfuchs D, Henkin Y, et al. (2008) Dietary Intervention Randomized Controlled Trial (DIRECT) Group. Weight Loss with a Low-Carbohydrate, Mediterranean, or Low-Fat Diet. N Engl J Med. 359: 229-241. [Crossref]

5. Schwarzfuchs D, Golan R, Shai I (2012) Four-year follow-up after two-year dietary interventions. $N$ Engl J Med 367: 1373-1374. doi: 10.1056/NEJMc1204792. [Crossref]

6. Meng Y, Bai H, Wang S, Li Z, Wang Q, Chen L (2017) Efficacy of low carbohydrate diet for type 2 diabetes mellitus management: A systematic review and metaanalysis of randomized controlled trials. Diabetes Res Clin Pract. 131: 124-131. doi: 10.1016/j.diabres.2017.07.006. [Crossref]

7. Ebe K, Ebe Y, Yokota S, Matsumoto T, Hashimoto M, Sakai Y, et al. (2004) Low Carbohydrate diet (LCD) treated for three cases as diabetic diet therapy. Kyoto Medical Association Journal 51: 125-129.

8. Bando H, Ebe K, Muneta T, Bando M, Yonei Y (2017) Effect of low carbohydrate diet on type 2 diabetic patients and usefulness of M-value. Diabetes Res Open J. 2017; 3(1): 9-16. doi: 10.17140/DROJ-3-130.

9. Sato J, Kanazawa A, Hatae C, Makita S, Komiya K, Shimizu T, et al. (2017) One year follow-up after a randomized controlled trial of a $130 \mathrm{~g} /$ day low-carbohydrate diet in patients with type 2 diabetes mellitus and poor glycemic control. PLoS One. 12 (12): e0188892. doi: 10.1371/journal.pone.0188892. eCollection 2017. [Crossref]

10. Tay J, Luscombe-Marsh ND, Thompson CH, et al. (2015) Comparison of low- and high-carbohydrate diets for type 2 diabetes management: a randomized trial. Am J Clin Nutr 102: 780-790. [Crossref]

11. Snorgaard O, Poulsen GM, Andersen HK, Astrup A. (2017) Systematic review and meta-analysis of dietary carbohydrate restriction in patients with type 2 diabetes. BMJ Open Diabetes Res Care 5: e000354.

12. Sato J, Kanazawa A, Makita S, et al. (2017) A randomized controlled trial of $130 \mathrm{~g} /$ day low-carbohydrate diet in type 2 diabetes with poor glycemic control. Clin Nutr 36: 992-1000. [Crossref]

13. MacLeod J, Franz MJ, Handu D, et al. (2017) Academy of Nutrition and Dietetics Nutrition Practice Guideline for Type 1 and Type 2 Diabetes in Adults: Nutrition Intervention Evidence Reviews and Recommendations. J Acad Nutr Diet 117: 1637-1658. [Crossref]
14. Lennerz BS, Barton A, Bernstein RK, et al. (2018) Management of Type 1 Diabetes With a Very Low-Carbohydrate Diet. Pediatrics 141.

15. Sanada M, Kabe C, Hata H, et al. (2018) Efficacy of a Moderately Low Carbohydrate Diet in a 36-Month Observational Study of Japanese Patients with Type 2 Diabetes. Nutrients 10. [Crossref]

16. The ARIC investigators (1989) The Atherosclerosis Risk in Communities (ARIC) Study: design and objectives. American Journal of Epidemiology, 129(4), 687-702. doi: 10.1093/oxfordjournals.aje.a115184. [Crossref]

17. Seidelmann SB, Claggett B, Cheng S, Henglin M, Shah A, et al. (2018) Dietary carbohydrate intake and mortality: a prospective cohort study and meta-analysis. Lancet Public Health. 3(9): e419-e428. doi: 10.1016/S2468-2667(18)30135-X.

18. American Diabetes Association (2018) Lifestyle Management: Standards of Medical Care in Diabetes-2018. Diabetes Care 41: S38-S50. [Crossref]

19. Van Horn L (2014) A diet by any other name is still about energy. JAMA 312: 900-901.

20. Noto H, Goto A, Tsujimoto T, Noda M (2013) Low-carbohydrate diets and all-cause mortality: a systematic review and meta-analysis of observational studies. PLoS One 8: e55030. [Crossref]

21. Dehghan M, Mente A, Zhang X, et al. (2017) Associations of fats and carbohydrate intake with cardiovascular disease and mortality in 18 countries from five continents (PURE): a prospective cohort study. Lancet 390: 2050-2062. [Crossref]

\section{Citation:}

Hiroshi Bando (2018) Clinical diversity of Low Carbohydrate Diet (LCD). J Clin Res Med Volume 1(4): 1-2. 